\title{
Well-being at a glance:with special focus on Geriatric population
}

\author{
Ramya Dwivedi* \\ *Department of Psychology, IILM University, India \\ *Corresponding author: Ramya Dwivedi, Department of Psychology, IILM University, Gurgaon, India
}

\section{Introduction}

The various models on wellbeing define wellbeing as a multidimensional construct integrating mental and physical health regarding health promotion by preventing disease. WHO also holds a holistic view of health comprising of physical mental and social wellbeing. Researches nowadays are more alert towards public health model rather than the medical model proposed during earlier times. The advent of positive psychology has led to a paradigm shift in health management strategies from pathogenic orientation which lays more emphasis on treatment and cure for illness to maltogenic approach that focuses on prevention of illness and health promotion. At an elementary level, wellbeing can be defined as how people perceive and evaluate the actions and activities in their life, the positive outcome that stands significant for individuals. The factors that can significantly affect the state of an individual's wellbeing are presence and the degree of positive relationship, self actualization, resilience, positive emotions contentment and purpose in life. Researches reveal global judgment of life satisfaction and feelings ranging between joy to depression to be included under wellbeing [1-6].

Numerous cross sectional and longitudinal researches have revealed that wellbeing is associated positively with the following variables $[5,7]$ :
a) Self-perceived health
b) Longevity
c) Healthy behaviors
d) Mental and physical illness
e) Social connectedness
f) Productivity
g) Factors in the physical and social environment

Research studies also state higher levels of wellbeing are associated with decreased risk of physical ailments like cardiovascular risk, injury and other types of illnesses; it improves immune functioning leading to quick recovery from ailments thus increasing the longevity. Further it is also related positively to job productivity and social contributions. The positive affect component of wellbeing is associated with extraversion and negative affect component to neuroticism [8-10].

\section{Aspects of Wellbeing}

Wellbeing is an umbrella term which includes many other aspects under it. Researchers have defined it as a diverse multidimensional construct to include physical, economic, social, emotional and psychological wellbeing (Figure 1). Psychological well being as a construct is considered to be stable and also something that is correlated positively with age, education extraversion and consciousness and negatively with neuroticism. The absence of disease does not signify wellbeing. Various models have been proposed to define psychological wellbeing. Some of the models discussed are the following: Jahoda's model, Seeman's model and Compton's model. Jahoda's model basically talks about characteristics of positive mental wellness by identifying six concepts under it.

\section{The Concepts Identified are the Following}

a) Attitude of an individual towards his own self

b) Self actualization

c) Integration

d) Autonomy

e) Perception of reality

f) Environmental mastery

Seeman's model is based on the behavioral subsystems of all human systems. It is based on the concept of organismic integration where organismic would refer to a pervasive process that comprehends all the subsystem such as biochemical, physiological, perceptual cognitive and interpersonal dimensions of behavior. The model proposed, looks like (Table 1). The horizontal dimension of the model emphasizes the point that wellbeing is a longitudinal development terms so as to include the concept of 
health as an ongoing process. Crompton's model finally proposes that psychological wellbeing can best be assumed by a tripartite model that includes subjective wellbeing, personal growth and religiosity. Research conducted by Crompton (2001) found that as people strive to gain greater psychological wellness they may seek interpersonal relationship to enhance self esteem, search for existentialism for self actualization. He further concluded that the conflict people experience in search of their happiness and good life may be related to a relative stable sense of identity. Correlates and determinants of individual wellbeing: Wellbeing is dependent upon good health, positive social relations and the basic/ primary needs of the individual, so as to quote the definition of health by W.H.O. "The physical, mental and social health of the individual". Individual wellbeing is determined by factors like autonomy, environmental mastery, life satisfaction, self acceptance, positive regard with others, and purpose in life and happiness. As individual correlates are based on the environment, might vary from one individual to the other. Personality and genes at the individual level are related to wellbeing. Researchers have shown that positive emotions are heritable to some degree suggesting that there may be some set points for emotions like happiness and sadness to be felt or experienced. Although it is not solely the genetic effects that would determine positive emotions, environmental factors would also play a role significantly. Genetic factors and personality factors would interact closely to influence the individual wellbeing of individuals. Age and gender as correlates of wellbeing show that men and women would almost have the similar levels of wellbeing, however with age [8] there has been found a $U$ shaped distribution wherein, wellbeing will be more among the younger and older population than the middle aged adults [1]. In terms of relationships, positive relations turn up to be one of the strongest correlates of wellbeing, having a positive effect altogether [10-12].

Table 1: Interpersonal dimensions of behavior.

\begin{tabular}{|c|c|}
\hline Vertical dimension & Horizontal dimension \\
\hline Subsystems & Developmental Process \\
\hline Interpersonal/ ecological & \\
\hline Person- to- person & \\
\hline Person- to- environment & \\
\hline Cognitive & \\
\hline Perceptual & \\
\hline Physiological & \\
\hline Biochemical & \\
\hline
\end{tabular}

\section{Some Reviews on Well Being Based on Report Prepared by CDC}

a) Employed women would show higher levels of wellbeing and also used fewer professional services to cope with stress than non employed ones, data from NHANES (1971-1975) revealed [13].

b) The other review from NHIS and quality of wellbeing scale (2001) found that males and females between the age group of 20-39 showed significantly better sense of wellbeing than the ones aged 40 years and older [7].

c) Data from BRFSS revealed that $8.6 \%$ of adults in US reported of never or rarely receiving emotional and social support [12].

\section{Statistics on Wellbeing}

Report presented on ageing statistics by World Health Organization shows that India's current elderly population is 60 million, which is projected to increase to 227 million in 2050 which shows an increase of 280 percent from the current situation. Similarly, glancing at China's current elderly population i.e. 65 and above, from 110 million shall likely reach to 330 million by 2050 (Figure 2). In a study conducted by global AGEing and adult health (SAGE) six major health risk factors viz. physical inactivity, current tobacco use, heavy alcohol consumption, high risk waisthip ratio, hypertension and obesity have been identified. The study reported that three of these six health risk factors rises with age however the patterns and percentage would vary by country. The pattern and percentage has been depicted in Figure 2 below. One of the goals of further researches in this direction might be to study and find out the outcome of such health conditions on the well being of the country's population. Number of disabilities seems to increase among the developing nation as the number of older people tends to increase. Health services in the developing nations needs improvement in their health services in order to understand the health risks faced by older people and accordingly plan for prevention and intervention. Further studies conducted in this direction show the health status score of males and females from six different countries. In the figure below (Figures 3 \& 4), it has been depicted that health status score declines with age, as expected. The graph shows the score for males is higher than females. However females tend to live longer than males on an average but have poorer health status. The health score in the figure ranges from 0 (worst health) to 100 (best health).

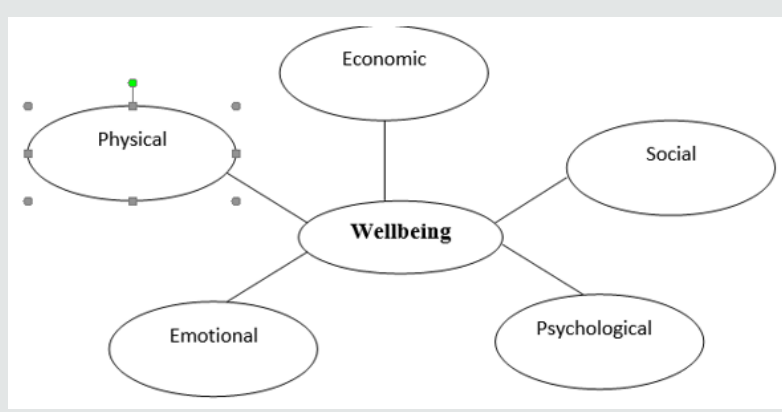

Figure 1: psychological Life cycle. 


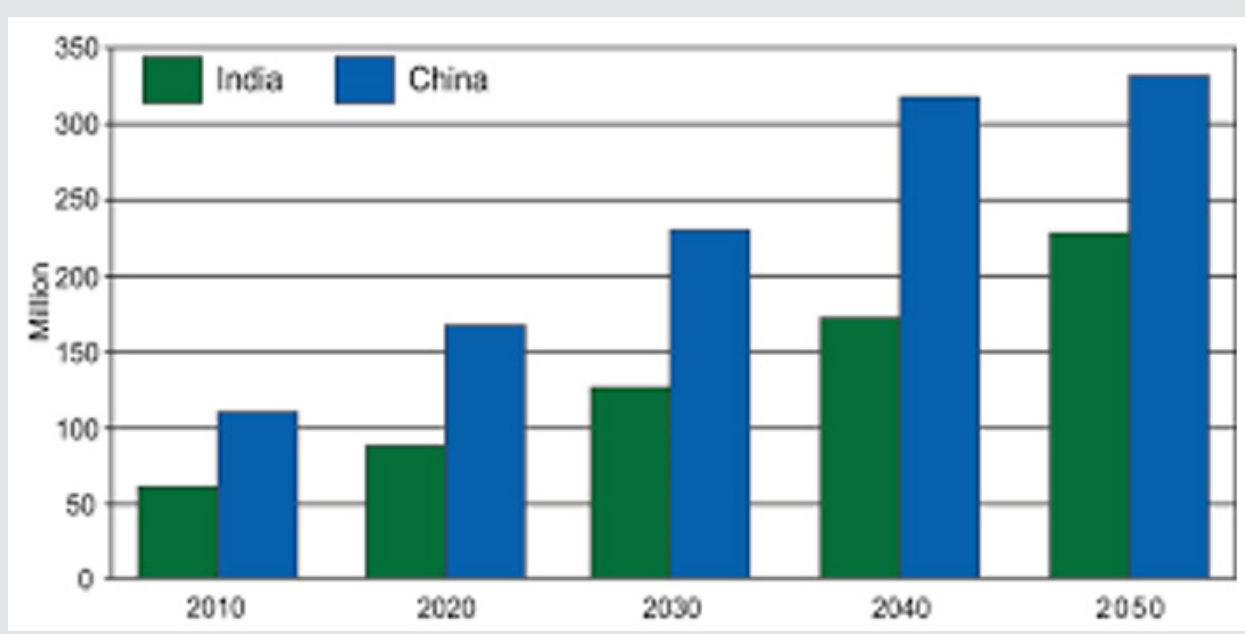

Figure 2: Showing the growth of elderly population aged 65 and above in India and China

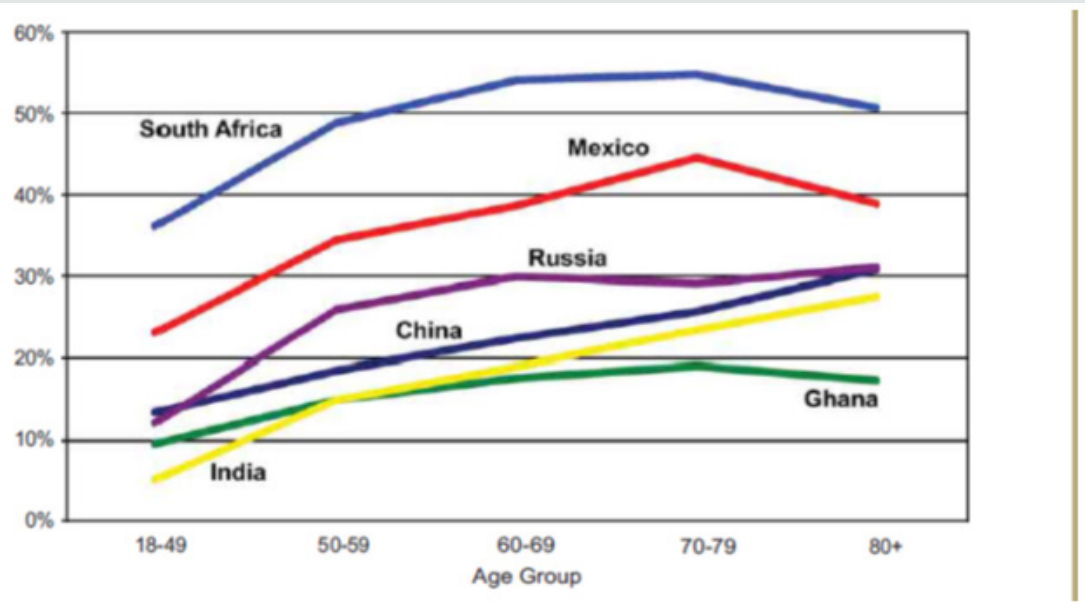

Figure 3: Showing the percentage of people with three major health risk factors country wise.

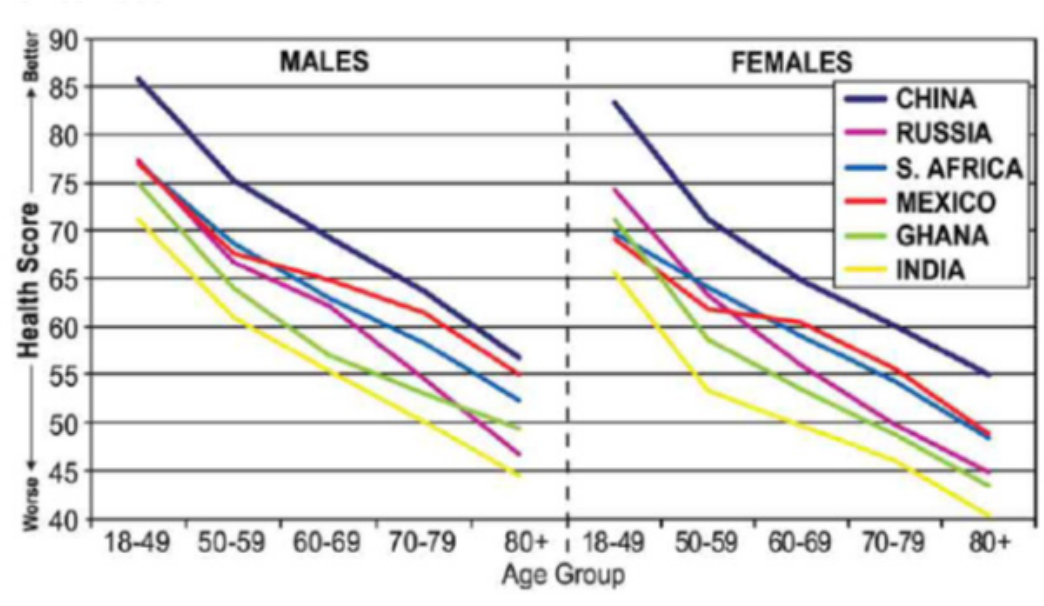

Figure 4: Showing the health status scores for six countries for both males and females.

\section{Conclusion}

India has acquired the label of "an ageing nation" with $7.7 \%$ of its population being more than 60 years. In India, the elderly population suffers from dual health issues i.e. either communicable or non communicable diseases. According to the Government of India statistics, cardiovascular diseases account for one third of elderly mortality. Respiratory disorders account for $10 \%$ mortality. As a concept, wellbeing can be defined as to how people evaluate their lives. Psychological well being as a construct comprises 
of positive affective state like happiness on one end and optimal functioning on the other end [14]. Thus accordingly, psychological wellbeing can be observed as a combination of feeling happy and functioning effectively. Studies and researches conducted further have reported that people who are high on psychological wellbeing report of feeling happy capable and good availability of social support and higher degrees of life satisfaction. The authors in a study concluded positive emotions as a potential promoting agent for population longevity and health [15]. Apart from the psychological factors it is also dependent upon physical health conditions that can be mediated by brain activation patterns neuro chemical effects and also genetic factors. The focus of any future research can be to increase the life expectancy rate of the elderly population and accordingly explore the ways of ensuring good quality of life with increasing age. With a special focus on the developing nations of the world, better medical aid and services should be provided by the community based health care centers and hospitals. The aim of these health care centers should be to plan interventions and improve the overall health conditions of the elderly population.

\section{References}

1. Argyle M (1999) Causes and correlates of happiness. In: D Kahneman E Diener, N Schwarz (Eds.) Well-being: the foundations of hedonic psychology. New York: Russell Sage Foundation, pp: 353-373.

2. Deci EL, Ryan RM (2008) Hedonal, eudaimonia, and well-being: An introduction. Journal of Happiness Studies 9(1): 1-11.

3. Diener E, Lucas RE (2003) Personality and subjective well-being. In: D. Kahneman, E. Diener, and N. Schwartz (eds.). Well-being: the foundations of hedonic psychology. New York: Russell Sage Foundation, pp: 213-229.

4. Diener E, Suh EM (2003) National differences in subjective well-being. In: D Kahneman, E Diener, N Schwarz. (eds.) Well-Being: The foundations of hedonic psychology. New York: Russell Sage Foundation Publications, pp: 434-450.

5. Diener E (2009) Assessing wellbeing: the collected works of Ed Diener New York: Springer.

6. Frey BS, Stutzer A (2002) Happiness and economics. Princeton NJ: Princeton University Press.

7. Hanmer (2006) Report of nationally representative values for the non institutionalized US adult population for 7 health-related quality of life scores. Medical Decision Making 26(4): 391-400.

8. Inglehart R Gender (2002) Aging and subjective well-being. International Journal Complementary Sociology 43(3-5): 391-408.

9. Lyubomirsky S, King L, Diener E (2005) The benefits of frequent positive affect: does happiness lead to success?. Psychology Bull 131(6): 803855.

10. Myers DG (2003) Close relationships and quality of life. In: D Kahneman, E Diener, N Schwarz. (eds.) Well Being: The foundations of hedonic psychology. New York: Russell Sage Foundation Publications, pp: 374391.

11. Steel P, Schmidt J, Schultz J (2008) Refining the relationship between personality and subjective well-being. Psychological Bulletin 134(1): 138-161.

12. Strine TW, Chapman DP, Balluz LS, Mokdad AH (2008) Health related quality of life and health behaviors by social and emotional support: Their relevance to psychiatry and medicine. Social Psychiatry and Psychiatric Epidemiology 43(2): 151-159.

13. Wheeler (1983) Employment, sense of well-being and use of professional services among women. Am Journal Public Health 73(8): 908-991.

14. World Health Organization Study on global AGEing and adult health (SAGE).

15. Xu J (2010) Roberts RE: The power of positive emotions: It's a matter of life or death-Subjective well-being and longevity over 28 years in a general population. Health Psychology 29(1): 9-19.

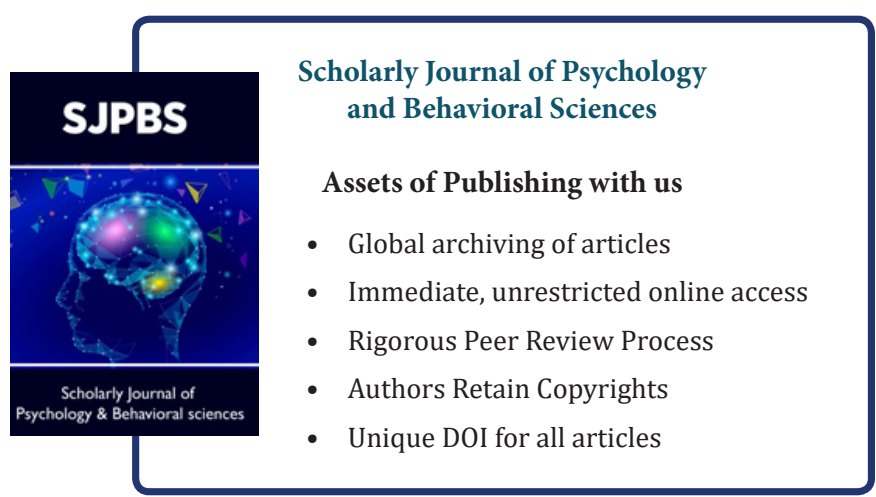

